\title{
A Novel Method to Fix Type C3 Distal Femur Fractures with Bone Defect Loss Using "Harms Cage"
}

\author{
Shyam R. Mukhi, Poonam Mukhi, Luv Mukhi, Kush Mukhi \\ Raj Orthopaedic Hospital, Mumbai, India \\ Email: smukhi123@gmail.com, poonam.mukhi@gmail.com, luvmukhi@gmai.com, kushiimukhii@gmail.com
}

How to cite this paper: Mukhi, S.R., Mukhi, P., Mukhi, L. and Mukhi, K. (2017) A Novel Method to Fix Type C3 Distal Femur Fractures with Bone Defect Loss Using "Harms Cage". Yangtze Medicine, 1, 96-103.

https://doi.org/10.4236/ym.2017.12009

Received: December 26, 2016

Accepted: June 18, 2017

Published: June 21, 2017

Copyright $\odot 2017$ by authors and Scientific Research Publishing Inc. This work is licensed under the Creative Commons Attribution International License (CC BY 4.0).

http://creativecommons.org/licenses/by/4.0/

\begin{abstract}
A case of compound C3 distal femur fracture with $12 \mathrm{~cm}$ bone defect. After thorough debridement, the Harms cage was used to reconstruct the medial column and the fracture was fixed with the locking distal femur plate laterally. The Harms cage prevents the cantilever effect and eliminates the need for medial plating. This avoids another medial incision and preserves medial biology. At 18 months' follow-up, plain radiographs demonstrated full reconstruction of the medial column with good range of motion at the knee joint. This technique avoids the need of dual plating in these fractures with good results.
\end{abstract}

\section{Keywords}

Distal Void, Distal Femur Fracture, Harms Cage

\section{Introduction}

Distal femoral fractures are usually caused by a high energy trauma. They are complicated by a high rate of systemic and local injuries to cartilage, ligaments and skin. Hence, they are difficult fractures to treat [1].

These fractures show a bimodal pattern with a marked variation in the number of fractures in relation to gender and age. A larger prevalence of fractures is observed either in young men (about 20 years old, traffic or sport) and in old women (about 70, fall at home, osteoporosis) [2].

Based on the common principles of the AO classification, type A fractures include extra-articular fractures and type B fractures are partial articular fractures, meaning parts of the articular surface remains in contact with the diaphysis of the femur Type $\mathrm{C}$ fractures include complete articular fractures with both condyles being detached from the diaphysis. The fracture types are further subdi- 
vided describing the degree of comminution and other characteristics. Further subdivision of type B fractures includes Bl (sagittal, lateral condyle), B2 (sagittal, medial condyle) and B3 (frontal, Hoffa type). Fracture type C is divided in C1 (articular simple, metaphyseal simple), C2 (articular simple, metaphyseal multifragmentary) and C3 (multifragmentary) [3] [4] (Figure 1).

Strict adherence to basic principles and techniques is required to prevent unsatisfactory results.

ORIF of these difficult fractures is justified only if:

1) The joint surfaces can be restored anatomically.

2) Fixation is sufficiently rigid that external immobilization is not required.

3) Rigidity of fixation is sufficient to allow early and active motion of the knee joint.

4) The skin and soft tissues are satisfactory for surgery.

There is no single surgical implant that can be used for all distal femoral fractures. Implant selection is determined by fracture pattern, patient age, bone density, and other injuries that the patient may have sustained. Rewarding results may be obtained with operative fracture intervention when appropriate patient and implant selection are made and the surgeon demonstrates meticulous skill and sound judgment [5].

A number of fixation devices such as blade plate, dynamic condylar screw, locking plates to more recently LISS, MIPPO and Distal femoral nails have been made available [6] [7] [8] [9].

For Distal femur type C3 fractures with severe comminution and bone defects it is recommended to do a dual plate fixation with bone grafting to achieve adequate stability [9] [10].

We present a novel method to fix type C3 distal femur fractures using a Harms cage with distal femur locking plates.
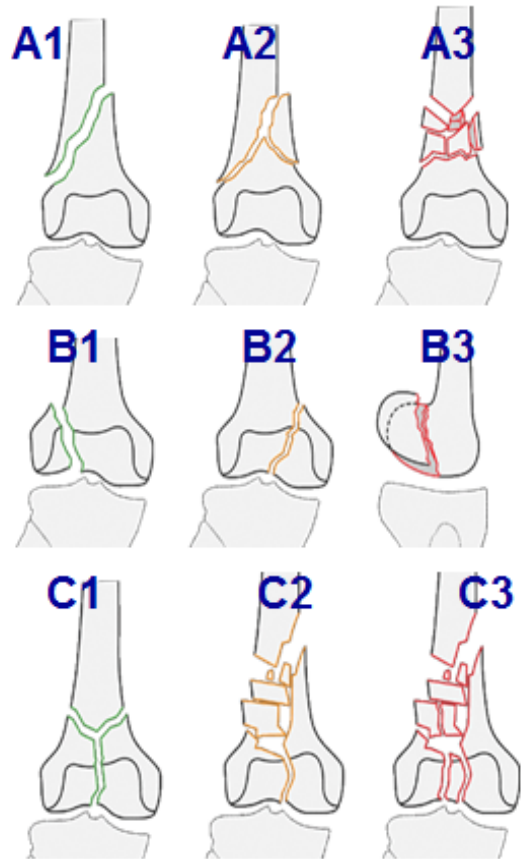

Figure 1. AO classification of distal femur fractures. 


\section{Case}

A 21 year old male presented to us after a vehicular accident with a type C3 compound right distal femur fracture with bone defect of about $12 \mathrm{~cm}$. Patient also had ipsilateral tibia shaft fracture. (Figure 2) There was no neuro vascular deficit. All blood investigations were normal. The tibia shaft fracture was treated with closed intra medullary interlocking nail immediately. Thorough debridement of the distal femur wound was done and surgery was carried out once the wound was clean.

\section{Procedure}

For the distal femur fracture the lateral approach was used and the fracture site was exposed. Hematoma was drained and the condylar fragments were reduced and fixed with cancellous screws and kirshner wires. Once the articular reduction was achieved we proceeded to build up the medial column. A Harms cage was taken of the size of the defect, in this case $12 \mathrm{~cm}$ and filled up with iliac bone grafts. The cage was inserted through the fracture site and punched all the way medially so that it filled up the medium column defect.Then the lateral column was anatomically reduced with the condyles and distal femur locking plate was applied (Figure 3). Patient was given an above knee cast and was kept nil weight bearing for 8 weeks. Physiotherapy was started at post op day 3. Patient was discharged at day 15 after stitch removal and AK cast reapplication. ROM exercises for the knee began at 6 weeks. Patient was allowed gradual weight bearing at 10 weeks. Patient was asked to follow up monthly and X-rays were taken.

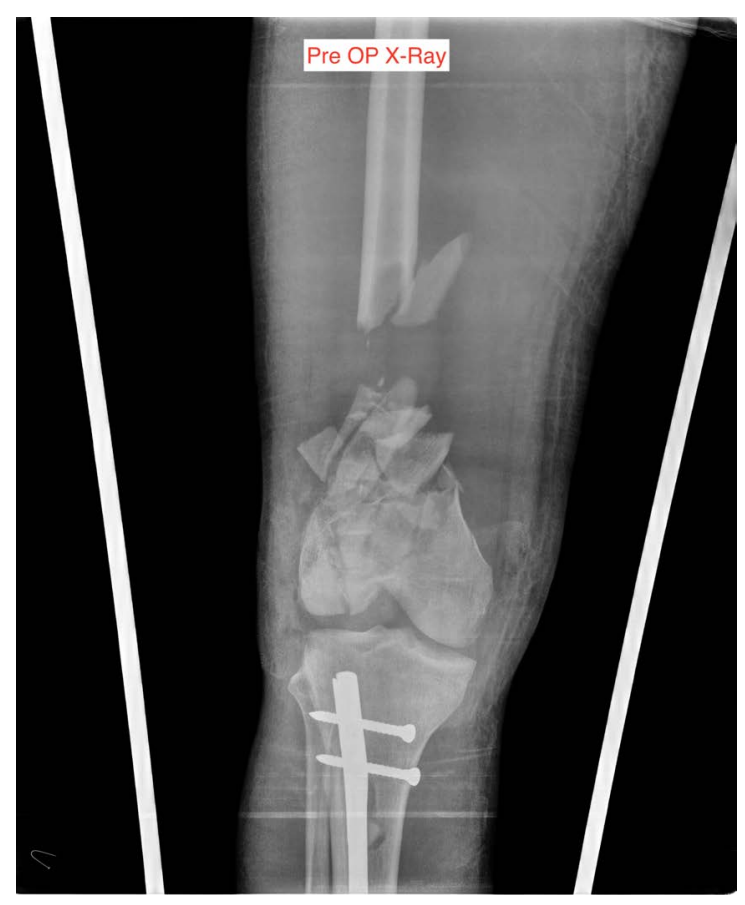

Figure 2. 21-year old male with compound C3 fracture of the right distal femur with $12 \mathrm{~cm}$ bone defect with ipsilateral shaft tibia fracture. 


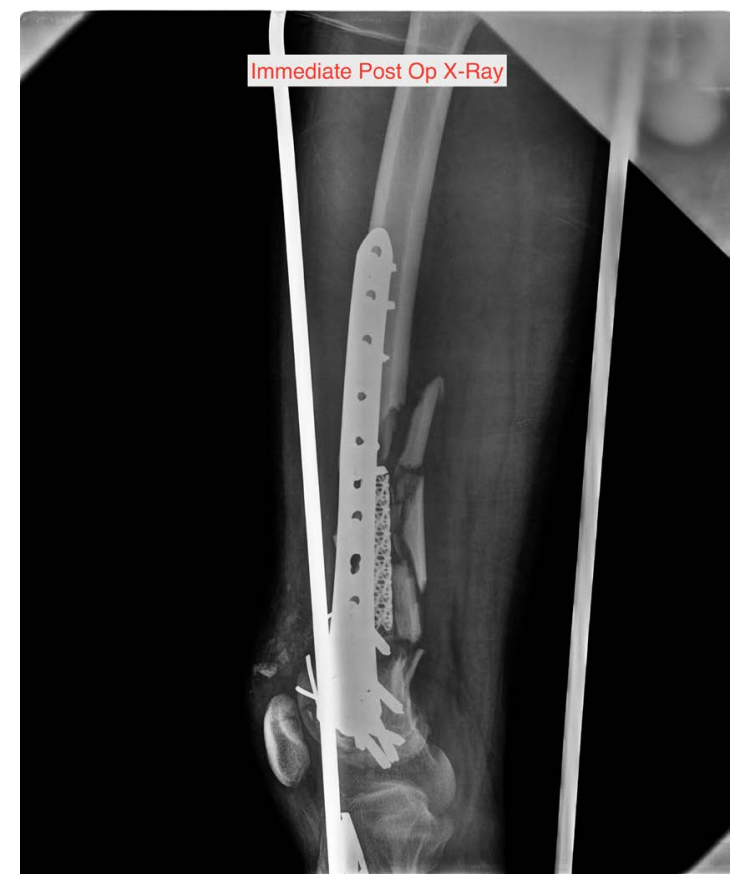

Figure 3. Immediate post-operative $x$-ray of the lateral view showing anatomically well reduced fracture fixed with the locking plate laterally and Harms cage with bone.

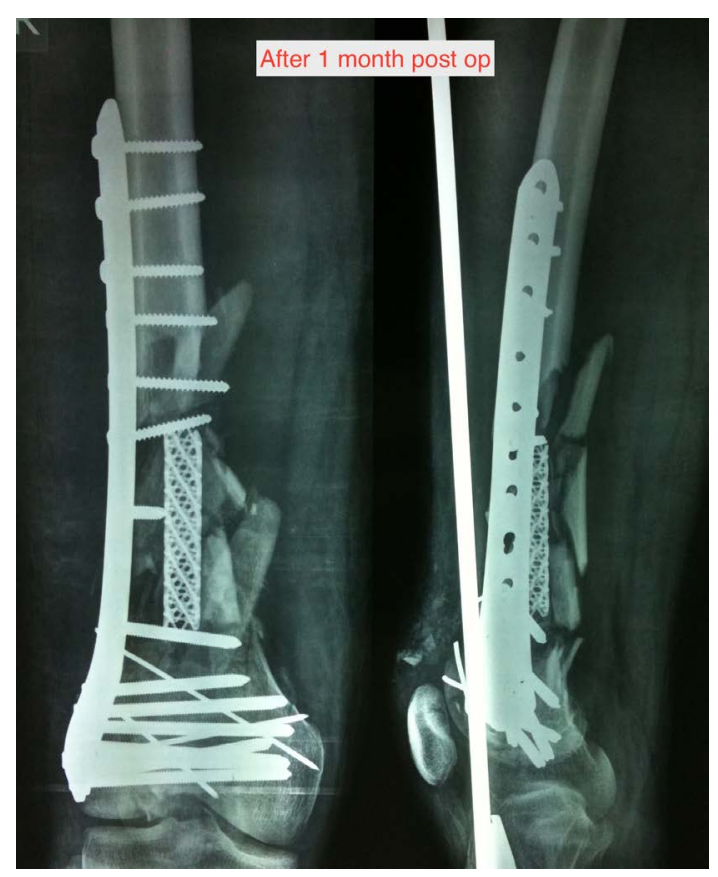

Figure 4. 1 month Post-operative Anteroposterior (AP) and Lateral views showing soft callus formation along the harms cage.

Soft callus formation started appearing at 5 weeks (Figure 4) and by 3 months distinct hard callus formation with reconstruction of the medial column was seen in both AP and Lateral views (Figure 5) Good bone union was achieved by 
6 months. By 18 months complete bony union with bony remodeling was visible on x-rays. (Figure 6) Patient had full extension and knee flexion up to 110 degrees and complete return of all his activities (Figure 7 and Figure 8).

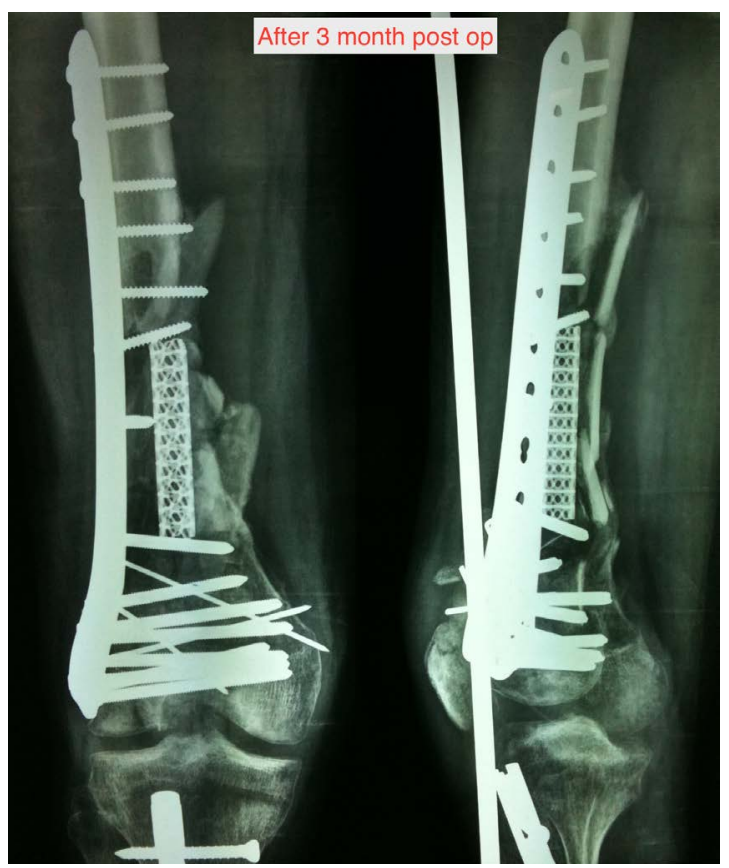

Figure 5. 3 month follow up of the patient showing distinct hard callus formation with reconstruction of the medial column in both AP and lateral views.

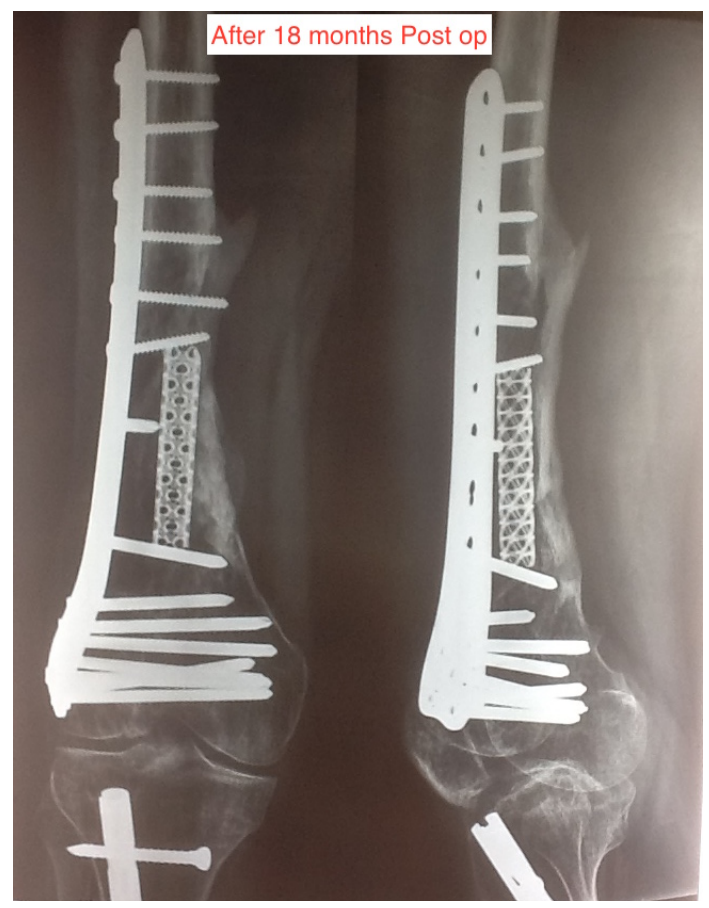

Figure 6. Complete bony union seen at 18 months in both AP and Lateral views with remodeling the fracture site. 


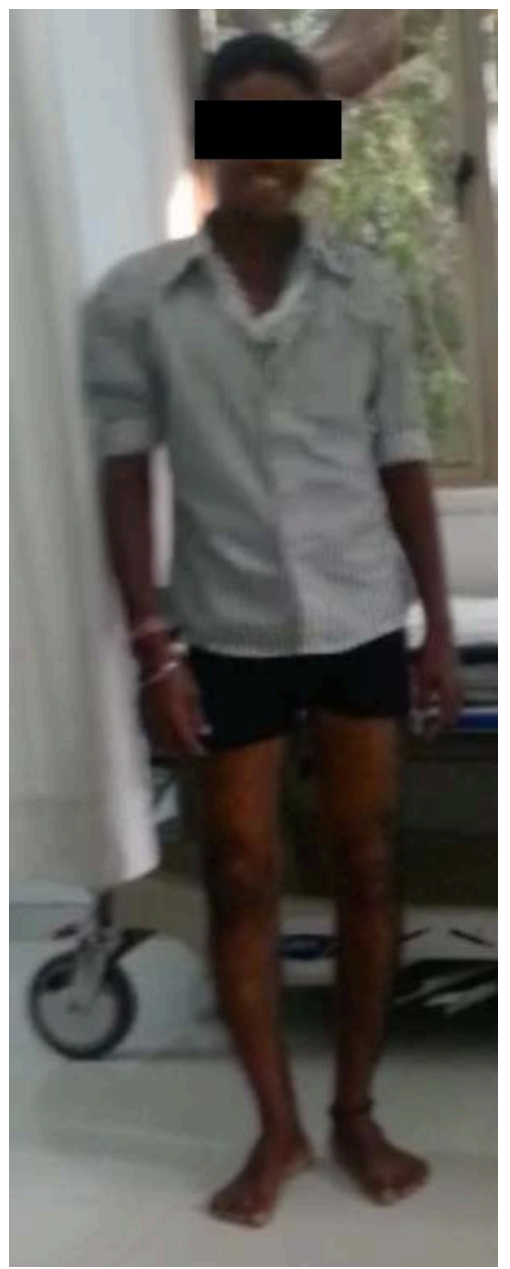

Figure 7. Clinical Photograph of the patient at 18 months standing.

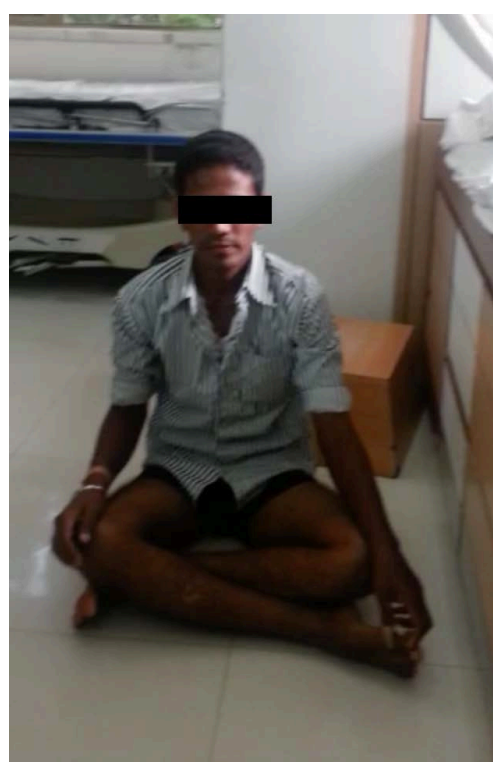

Figure 8. Clinical Photograph of the patient at 18 months cross-legged sitting on the floor. 


\section{Discussion}

The Harms cage has been used in orthopaedic trauma to fill in segmental diaphysial bone defects with success. [11]-[19] In the spine, the Harms cage is used as a mechanical strut anteriorly to prevent kyphosis due to the cantilever effect. We have extrapolated both these facts to the femur where the Harms cage acts as mechanical strut and reconstructs the medial column of the femur.

It prevents the cantilever effect and prevents the failure or breakage of the lateral implant.

\section{Advantages of This Method}

1) Reconstruction of the medial column in a single incision.

2) Less periosteal stripping.

3) No risk of damage to the medial neurovascular bundle.

4) Decreased chances of infection as lesser soft tissue handling.

5) Preserves Biology medially.

\section{References}

[1] Krettek, C., et al. (1997) Distal Femoral Fractures. Swiss Surgery, 6, 263-278.

[2] Martinet, O., et al. (2000) The Epidemiology of Fractures of the Distal Femur. Injury, 31, 62-63, 81, 86, 90, 94. https://doi.org/10.1016/s0020-1383(00)80034-0

[3] Müller, M.E., Nazarian, S. and Koch, P. (1987) Classification AO des Fractures. Springer-Verlag, New York.

[4] Neer, C.S., Grantham, S.A. and Shelton, M.L. (1967) Supracondylar Fracture of the Adult Femur. A Study of One Hundred and Ten Cases. Journal of Bone \& Joint Surgery-American, 49, 591-613. https://doi.org/10.2106/00004623-196749040-00001

[5] Johnson, K.D. and Hicken, G. (1987) Distal Femoral Fractures. The Orthopedic Clinics of North America, 18, 115-132.

[6] Martinet, O. (1996) The Mechanics of Internal Fixation of Fractures of the Distal Femur: A Comparison of the Condylar Plate (CP) with the Condylar Screw (DCS). Master's Thesis, University Zürich, Zürich.

[7] Synthes (2001) Locking Condylar Plate: Technique Guide. Paoli, PA.

[8] Zlowodzki, M., et al. (2004) Biomechanical Evaluation of the Less Invasive Stabilization System, Angled Blade Plate, and Retrograde Intramedullary Nail for the Internal Fixation of Distal Femur Fractures. Unfallchirurg, 107, 1107-1108.

[9] Jazrawi, Laith M., et al. (2000) New Technique for Treatment of Unstable Distal Femur Fractures by Locked Double-Plating: Case Report and Biomechanical Evaluation. Journal of Trauma and Acute Care Surgery, 48, 87. https://doi.org/10.1097/00005373-200001000-00015

[10] Solomon, L.B., Callary, S.A., Boopalan, P.R., Chakrabarty, A., Costi, J.J. and Howie, D.W. (2013) Impaction Bone Grafting of Segmental Bone Defects in Femoral Non-Unions. Acta Orthopaedica Belgica, 79, 64-70.

[11] Attias, N., Lehman, R.E., Bodell, L.S. and Lindsey, R.W. (2005) Surgical Management of a Long Segmental Defect of the Humerus Using a Cylindrical Titanium Mesh Cage and Plates: A Case Report. Journal of Orthopaedic Trauma, 19, 211-216. https://doi.org/10.1097/00005131-200503000-00011 
[12] Attias, N. and Lindsey, R.W. (2006) Case Reports: Management of Large Segmental Tibial Defects Using a Cylindrical Mesh Cage. Clinical Orthopaedics and Related Research, 450, 259-266. https://doi.org/10.1097/01.blo.0000223982.29208.a4

[13] Chmell, M.J., McAndrew, M.P., Thomas, R. and Schwartz, H.S. (1995) Structural Allografts for Reconstruction of Lower Extremity Open Fractures with 10 Centimeters or More of Acute Segmental Defects. Journal of Orthopaedic Trauma, 9, 222 226. https://doi.org/10.1097/00005131-199506000-00007

[14] Cobos, J.A., Lindsey, R.W. and Gugala, Z. (2000) The Cylindrical Titanium Mesh Cage for Treatment of a Long Bone Segmental Defect: Description of a New Technique and Report of Two Cases. Journal of Orthopaedic Trauma, 14, 54-59. https://doi.org/10.1097/00005131-200001000-00011

[15] Ostermann, P.A., Haase, N., Rübberdt, A., Wich, M. and Ekkernkamp. A. (2002) Management of a Long Segmental Defect at the Proximal Meta-Diaphyseal Junction of the Tibia Using a Cylindrical Titanium Mesh Cage. Journal of Orthopaedic Trauma, 16, 597-601. https://doi.org/10.1097/00005131-200209000-00010

[16] Clements, J.R., Carpenter, B.B. and Pourciau, J.K. (2008) Treating Segmental Bone Defects: A New Technique. Journal of Foot and Ankle Surgery, 47, 350-356. https://doi.org/10.1053/j.jfas.2008.04.006

[17] Lasanianos, N.G., Kanakaris, N.K. and Giannoudis, P.V. (2010) Current Management of Long Bone Large Segmental Defects. Orthopaedics and Trauma, 24, 2.

[18] Lindsey, R.W., Gugala, Z., Milne, E., Sun, M., Gannon, F.H. and Latta, L.L. (2006) The Efficacy of Cylindrical Titanium Mesh Cage for the Reconstruction of a Critical-Size Canine Segmental Femoral Diaphyseal Defect. Journal of Orthopaedic Research, 24, 1438-1453. https://doi.org/10.1002/jor.20154

[19] Bullens, P.H.J., Schreuder, B.H.W., de Waal Malefijt, M.C., Veth, R.P.H., Buma, P. and Verdonschot, N. (2009) The Stability of Impacted Morsellized Bone Grafts in a Metal Cage under Dynamic Loaded Conditions: An in Vitro Reconstruction of a Segmental Diaphyseal Bone Defect. Archives of Orthopaedic and Trauma Surgery, 129, 575-581. https://doi.org/10.1007/s00402-009-0821-0

\section{Scientific Research Publishing}

\section{Submit or recommend next manuscript to SCIRP and we will provide best} service for you:

Accepting pre-submission inquiries through Email, Facebook, LinkedIn, Twitter, etc. A wide selection of journals (inclusive of 9 subjects, more than 200 journals)

Providing 24-hour high-quality service

User-friendly online submission system

Fair and swift peer-review system

Efficient typesetting and proofreading procedure

Display of the result of downloads and visits, as well as the number of cited articles

Maximum dissemination of your research work

Submit your manuscript at: http://papersubmission.scirp.org/

Or contact ym@scirp.org 